\title{
Cancer incidence and mortality among underground and surface goldminers in Western Australia
}

\author{
S Peters ${ }^{*, 1}$, A Reid ${ }^{1,2}$, L Fritschi ${ }^{1}$, A W (Bill) Musk ${ }^{2,3}$ and N de Klerk ${ }^{2,4}$ \\ ${ }^{1}$ Western Australian Institute for Medical Research, University of Western Australia, Nedlands, Western Australia 6009, Australia; \\ ${ }^{2}$ School of Population Health, University of Western Australia, Nedlands, Western Australia 6009, Australia; ${ }^{3}$ Department of \\ Respiratory Medicine, Sir Charles Gairdner Hospital, Nedlands, Western Australia 6009, Australia and ${ }^{4}$ Telethon Institute for Child \\ Health Research, Centre for Child Health Research, University of Western Australia, Subiaco, Western Australia 6008, Australia
}

Background: In a cohort of goldminers, we estimated cancer mortality and incidence, for both surface and underground workers, and we examined the hypothesis that (underground) mining may be protective against prostate cancer.

Methods: Standardised mortality and incidence ratios (SMRs and SIRs) and 95\% confidence intervals (CI) were calculated to compare cancer mortality and incidence of former goldminers with that of the general male population. Internal comparisons on duration of underground work were examined using Cox regression.

Results: During 52608 person-years of follow-up among 2294 goldminers, 1922 deaths were observed. For any cancer, mortality was increased for the total group of miners (SMR $=1.27,95 \% \mathrm{Cl} 1.16-1.39)$. In the Cox models, lung cancer mortality and incidence were particularly increased among underground miners, even after adjustment for smoking. The SMR for prostate cancer suggested a lower risk for underground miners, whereas incidence of prostate cancer was significantly increased (SIR $=1.31,95 \%$ Cl 1.07-1.60) among underground miners.

Conclusion: Overall cancer mortality and incidence was higher among Western Australian goldminers compared with the general male population, particularly for underground mining. This study does not support the hypothesis that miners have a decreased risk of prostate cancer.

Miners have been identified with a lower risk of prostate cancer in recent publications (Girschik et al, 2010; Walsh et al, 2012). The effect appeared to be more pronounced for underground miners. The potential explanations that were put forward by Girschik et al (2010) for the group of miners as a whole were a healthy worker effect or the higher level of physical activity among miners compared with the general population. While the first is unlikely for prostate cancer, the latter would not result in different risks for surface or underground miners. A third explanation, the 'melatonin hypothesis', was postulated that would explain lower risk for underground miners. Both surface and underground miners commonly do night shifts, but the lack of ambient light exposure among underground miners may result in increased levels of melatonin (Girschik et al, 2010). This hypothesis was supported by findings in a German cohort of uranium miners (Walsh et al, 2012).

On the other hand, the numbers of years worked in hard rock underground mines have been associated with an excess lung cancer risk (Hodgson and Jones, 1990; Chau et al, 1993; De Klerk et al, 1995). Underground mining is characterised by high exposures to diesel engine exhaust (Pronk et al, 2009) and silica exposure has been particularly high in the Kalgoorlie underground goldmines (Steenland et al, 2001). Both these exposures have been shown to increase the risk of lung cancer (Steenland et al, 2001; 
Pronk et al, 2009; Attfield et al, 2012). Asbestos fibres have been found in Kalgoorlie goldmines (Lee et al, 1999), whereas exposure to other potential lung carcinogens (radon and arsenic) appeared to be low (Armstrong et al, 1979).

In contrast to lung cancer, men diagnosed with prostate cancer are more likely to die from another cause (Epstein et al, 2012). As the cause of death as reported on death certificates is used to estimate mortality ratios, these ratios might not be adequate to describe altered risks for prostate cancer. Standardised incidence ratios (SIR) based on numbers from cancer registries should therefore give a more precise estimate.

Our objectives were to estimate lung and prostate cancer mortality and incidence, for both surface and underground miners, and to examine the hypothesis that (underground) mining may be protective against prostate cancer.

\section{METHODS}

Kalgoorlie is a Western Australian (WA) mining town, $550 \mathrm{~km}$ east of the capital city of Perth. A cohort of 2294 male goldminers was established from surveys of respiratory symptoms, smoking and lung function performed in Kalgoorlie (1961-1975). Detailed information was collected on smoking and medical history. Updated smoking details were obtained from 250 subjects via an additional questionnaire in 2000. Full employment details were recorded on miners' health record cards (De Klerk and Musk, 1998). Miners were required to have annual chest X-rays as long as they were employed as miners. Dates of employment at each mine and job descriptions were recorded at each presentation. On the basis of this information, the number of months worked underground for each job was assigned. Fourteen subjects were deleted from the cohort because no employment data could be obtained.

The cohort was linked to WA mortality records up to 31 December 2009. Expected numbers of death were estimated using age- and period-specific cancer mortality rates calculated for the WA male population in 5-year periods from 1970 to 2009. Mortality rates for the period 1970-1974 were used to calculate expected rates from the person-years accumulated for the first period of 1961-1969 as period-specific rates were not available for those years. Vital status of 329 individuals (46 surface-only workers (12\%); 283 ever-underground miners (15\%)) was unknown in December 2009. These miners were treated as alive until last observed date and then censored. The cohort was also linked to the WA cancer registry, with incidence data available from 1982 until 31 December 2011. Data linkage was approved by the UWA human research ethics committee.

Standardised mortality ratios (SMR) and SIRs for any cancer, lung and prostate cancer were calculated as the ratio of the observed events to expected events using Stata v12.0 (StataCorp LP, College station, TX, USA).
Cox proportional hazard models were fitted to examine the risk of working underground on cancer within the cohort, using PROC PHREG in SAS v9.3 software (SAS Institute Inc., Cary, NC, USA). Hazard ratios (HR) and corresponding 95\% confidence intervals (CI) adjusted for year of birth were calculated for the whole cohort. Duration of work underground was modelled as a time-dependent variable. Models for lung and any cancer were additionally adjusted for smoking duration (in years).

\section{RESULTS}

A total of 1922 deaths were observed among 2294 miners during 52608 person-years of observation. For ever-underground miners, 1577 deaths were observed for 42780 person-years, and there were 345 deaths among miners who had only worked at the surface (9828 person-years). Median year of birth was 1913. The median length of follow-up was 22 years and the median length of employment underground for those who ever worked as an underground miner was 20 years. Total time worked as a miner was similar between the surface-only and ever-underground miners, with medians of 33 and 32 years, respectively. Seventysix per cent of surface-only workers and $87 \%$ ever-underground miners were ever-smokers. Mean duration of smoking was 45 years in both groups of miners.

Death from any cause was significantly elevated by $38 \%$ in the full cohort compared with the general population (Table 1). Cancer mortality was significantly increased among underground miners $(\mathrm{SMR}=1.32,95 \%$ CI $1.20-1.46)$, as was mortality from lung cancer specifically $(\mathrm{SMR}=1.82,95 \%$ CI $1.56-2.13)$. No altered mortality of prostate cancer was observed for the cohort as a whole, although it was marginally lower for underground miners $(\mathrm{SMR}=0.81,95 \%$ CI $0.55-1.20)$.

Incidence of any cancer, lung and prostate cancer were significantly increased among the miners compared with the general population (Table 2). Stratified analyses by worker location showed similar results for prostate cancer, whereas the increased risk of lung cancer was more pronounced among ever-underground miners.

There was a clear trend in the HRs for duration of work underground and any cause of death $\left(P_{\text {trend }} 0.003\right.$, Table 3$)$. An indication of a trend was observed for overall cancer mortality and for lung cancer mortality and incidence. No trend was observed for prostate cancer-specific mortality or incidence with working underground.

\section{DISCUSSION}

This study has shown increased mortality from any cause among miners, with a significant trend for total months worked

Table 1. SMR and 95\% Cl overall and by worker location (1961-2009)

\begin{tabular}{|c|c|c|c|c|c|c|c|c|c|}
\hline \multirow[b]{2}{*}{ Cause of death } & \multicolumn{3}{|c|}{$\begin{array}{l}\text { Full cohort }(n=2294) \\
52608 \text { person-years }\end{array}$} & \multicolumn{3}{|c|}{$\begin{array}{l}\text { Surface only }(n=400) \\
9828 \text { person-years }\end{array}$} & \multicolumn{3}{|c|}{$\begin{array}{l}\text { Ever underground }(n=1894) \\
42780 \text { person-years }\end{array}$} \\
\hline & $n$ & SMR & $95 \% \mathrm{Cl}$ & $n$ & SMR & $95 \% \mathrm{Cl}$ & $n$ & SMR & $95 \% \mathrm{Cl}$ \\
\hline Any cause & 1922 & 1.38 & $1.32-1.44$ & 345 & 1.35 & $1.22-1.50$ & 1577 & 1.42 & $1.35-1.49$ \\
\hline Any cancer & 455 & 1.27 & $1.16-1.39$ & 76 & 1.06 & $0.84-1.32$ & 379 & 1.32 & $1.20-1.46$ \\
\hline Lung cancer & 182 & 1.64 & $1.42-1.90$ & 20 & 0.91 & $0.59-1.41$ & 162 & 1.82 & $1.56-2.13$ \\
\hline Prostate cancer & 37 & 0.94 & $0.68-1.30$ & 11 & 1.44 & $0.82-2.54$ & 25 & 0.81 & $0.55-1.20$ \\
\hline
\end{tabular}


Table 2. SIR and 95\% Cl overall and by worker location (1982-2011)

\begin{tabular}{|c|c|c|c|c|c|c|c|c|c|}
\hline & \multicolumn{3}{|c|}{$\begin{array}{l}\text { Full cohort }(n=1373) \\
16450 \text { person-years }\end{array}$} & \multicolumn{3}{|c|}{$\begin{array}{l}\text { Surface only }(n=223) \\
2793 \text { person-years }\end{array}$} & \multicolumn{3}{|c|}{$\begin{array}{c}\text { Ever underground }(n=1150) \\
13657 \text { person-years }\end{array}$} \\
\hline & $n$ & SIR & $95 \% \mathrm{Cl}$ & $n$ & SIR & $95 \% \mathrm{Cl}$ & $\boldsymbol{n}$ & SIR & $95 \% \mathrm{Cl}$ \\
\hline Any cancer & 477 & 1.50 & $1.37-1.64$ & 84 & 1.37 & $1.11-1.70$ & 376 & 1.47 & $1.32-1.62$ \\
\hline Lung cancer & 110 & 1.89 & $1.57-2.28$ & 15 & 1.33 & $0.80-2.20$ & 95 & 2.03 & $1.66-2.48$ \\
\hline Prostate cancer & 122 & 1.32 & $1.10-1.57$ & 25 & 1.33 & $0.90-1.97$ & 97 & 1.31 & $1.07-1.60$ \\
\hline
\end{tabular}

Abbreviations: $\mathrm{Cl}=$ confidence intervals; $\mathrm{SMR}=$ standardised incidence ratio.

Table 3. HR and $95 \% \mathrm{Cl}$ for duration worked underground-mortality and incidence

Never underground (reference)

\section{$<20$ years underground ${ }^{a}$}

$20+$ years underground ${ }^{a}$

$\boldsymbol{P}_{\text {trend }}^{\mathrm{b}}$

\begin{tabular}{|c|c|c|c|c|c|c|c|c|}
\hline & $n$ & $n$ & $H^{c}$ & $95 \% \mathrm{Cl}$ & $n$ & $H^{c}$ & $95 \% \mathrm{Cl}$ & \\
\hline \multicolumn{9}{|l|}{ Mortality } \\
\hline $\begin{array}{l}\text { Any cause } \\
\text { Any cancer } \\
\text { Lung cancer } \\
\text { Prostate cancer }\end{array}$ & $\begin{array}{c}345 \\
76 \\
20 \\
12\end{array}$ & $\begin{array}{c}724 \\
178 \\
74 \\
12\end{array}$ & $\begin{array}{l}1.21 \\
1.29 \\
1.93 \\
0.63\end{array}$ & $\begin{array}{l}1.06-1.37 \\
0.98-1.69 \\
1.17-3.16 \\
0.28-1.40\end{array}$ & $\begin{array}{c}853 \\
201 \\
88 \\
13\end{array}$ & $\begin{array}{l}1.25 \\
1.31 \\
1.93 \\
0.64\end{array}$ & $\begin{array}{l}1.10-1.42 \\
1.00-1.71 \\
1.19-3.15 \\
0.30-1.40\end{array}$ & $\begin{array}{l}0.003 \\
0.134 \\
0.115 \\
0.694\end{array}$ \\
\hline \multicolumn{9}{|l|}{ Incidence } \\
\hline $\begin{array}{l}\text { Any cancer } \\
\text { Lung cancer } \\
\text { Prostate cancer }\end{array}$ & $\begin{array}{l}84 \\
15 \\
25\end{array}$ & $\begin{array}{l}195 \\
39 \\
52\end{array}$ & $\begin{array}{l}1.04 \\
1.09 \\
1.08\end{array}$ & $\begin{array}{l}0.80-1.34 \\
0.60-2.00 \\
0.67-1.74\end{array}$ & $\begin{array}{l}198 \\
56 \\
45\end{array}$ & $\begin{array}{l}1.15 \\
1.57 \\
0.99\end{array}$ & $\begin{array}{l}0.89-1.49 \\
0.88-2.77 \\
0.61-1.63\end{array}$ & $\begin{array}{l}0.344 \\
0.096 \\
0.987\end{array}$ \\
\hline
\end{tabular}

Abbreviations: $\mathrm{Cl}=$ confidence intervals; $\mathrm{HR}=$ hazard ratio.

${ }^{a_{M}}$ Median duration of underground work was 240 months (20 years) among ever-underground miners.

${ }^{b} P$-value for trend (continuous duration: months worked underground).

${ }^{\mathrm{c}}$ All HRs are adjusted for year of birth, HRs for lung and any cancer are additionally adjusted for smoking (duration in years).

underground. Cancer mortality and incidence were increased. For lung cancer, this increase was particularly seen among underground miners. The SMR for prostate cancer pointed towards a lower risk for underground miners, but the incidence data showed a significantly increased incidence among underground miners.

The overall increased mortality in the goldminers' cohort is, besides cancers, mainly attributable to pneumoconiosis $(\mathrm{SMR}=11.2,95 \%$ CI 8.4-14.8) (De Klerk and Musk, 1998). The increased mortality from cancer among miners appeared to be mainly driven by lung cancer, as the SMR for any cancer dropped to 1.10 (95\% CI $0.98-1.24$ ) when lung cancer was excluded (data not shown).

The finding of an increased risk of lung cancer among minersin particular underground miners-supports previous findings in this cohort (De Klerk et al, 1995; De Klerk and Musk, 1998). Increased risks of lung cancer in relation to duration of underground hard rock mining have also been described in other cohorts. Hodgson and Jones (1990) observed an overall SMR of 1.58 for lung cancer with a significant linear trend for years worked underground among tin miners (Hodgson and Jones, 1990). In a French iron mine, significantly increased mortality from lung cancer was observed with SMRs increasing by duration worked underground: 1.81 for $1-19$ years, 4.23 for $20-29$ years and 6.25 for $30+$ years (Chau et al, 1993).

Smoking may explain part of the observed differences in lung cancer risk, as more underground miners were smokers. However, our Cox regression models were adjusted for smoking duration and showed a significantly increased risk for underground miners compared with surface-only. The main causative agents suggested for lung cancer risk in underground mines are diesel engine exhaust and respirable silica (Steenland et al, 2001; Attfield et al, 2012). Further analyses, for example, by looking on a job level, might explain the association with these exposures better in this cohort.

No protective effect of mining on prostate cancer was observed in the current analyses. Although mortality data might have suggested a slight decreased risk for underground mining, incidence data showed a clearly increased risk with a SIR of 1.27 for all miners (95\% CI 1.07-1.52). No difference was observed between surface and underground miners. As men with prostate cancer are more likely to die from another cause (Epstein et al, 2012), mortality data are probably less accurate than incidence data when studying risk of prostate cancer.

As mines operate $24 \times 7$, workers are required to do regular night shifts. In 2007, shiftwork involving circadian disruption was classified as being probably carcinogenic to humans (Straif et al, 2007). The circadian system gets disturbed by exposure to light at night, leading to alterations in sleep patterns, suppression of melatonin production and deregulation of circadian genes involved in cancer-related pathways (Stevens et al, 2007). The available studies on prostate cancer and night shift were mainly suggestive of a positive association, but evidence of a causal association is as yet insufficient (Kolstad, 2008; Sigurdardottir et al, 2012). Our results 
may add to the body of evidence for an association between night shifts and prostate cancer.

Overall cancer mortality and incidence was higher among Western Australian goldminers compared with the general population, especially for lung cancer and particularly for underground mining. This study does not support the hypothesis that miners have a decreased risk of prostate cancer.

\section{ACKNOWLEDGEMENTS}

We thank Nola Olsen, Jan Sleith and Robin Mina for cohort data provision and Dr Timothy Threlfall of the Western Australian Cancer Registry for providing cancer registry data.

\section{REFERENCES}

Armstrong BK, McNulty JC, Levitt LJ, Williams KA, Hobbs MS (1979) Mortality in gold and coal miners in Western Australia with special reference to lung cancer. $\mathrm{Br} J$ Ind Med 36: 199-205.

Attfield MD, Schleiff PL, Lubin JH, Blair A, Stewart PA, Vermeulen R, Coble JB, Silverman DT (2012) The diesel exhaust in miners study: a cohort mortality study with emphasis on lung cancer. J Natl Cancer Inst 104: 869-883.

Chau N, Benamghar L, Pham QT, Teculescu D, Rebstock E, Mur JM (1993) Mortality of iron miners in Lorraine (France): relations between lung function and respiratory symptoms and subsequent mortality. $\mathrm{Br} J$ Ind Med 50: 1017-1031.

De Klerk NH, Musk AW (1998) Silica, compensated silicosis, and lung cancer in Western Australian goldminers. Occup Environ Med 55: 243-248.

De Klerk NH, Musk AW, Tetlow S, Hansen J, Eccles JL (1995) Preliminary study of lung cancer mortality among Western Australian gold miners exposed to silica. Scand J Work Environ Health 21(Suppl 2): 66-68.
Epstein MM, Edgren G, Rider JR, Mucci LA, Adami HO (2012) Temporal trends in cause of death among Swedish and US men with prostate cancer. J Natl Cancer Inst 104: 1335-1342.

Girschik J, Glass D, Ambrosini GL, Fritschi L (2010) Could mining be protective against prostate cancer? A study and literature review. Occup Environ Med 67: 365-374.

Hodgson JT, Jones RD (1990) Mortality of a cohort of tin miners 1941-86. Br J Ind Med 47: 665-676.

Kolstad HA (2008) Nightshift work and risk of breast cancer and other cancers-a critical review of the epidemiologic evidence. Scand J Work Environ Health 34: 5-22.

Lee YC, De Klerk NH, Musk AW (1999) Asbestos-related pleural disease in Western Australian gold-miners. Med J Aust 170: 263-265.

Pronk A, Coble J, Stewart PA (2009) Occupational exposure to diesel engine exhaust: a literature review. J Expo Sci Environ Epidemiol 19: 443-457.

Sigurdardottir LG, Valdimarsdottir UA, Fall K, Rider JR, Lockley SW, Schernhammer E, Mucci LA (2012) Circadian disruption, sleep loss, and prostate cancer risk: a systematic review of epidemiologic studies. Cancer Epidemiol Biomarkers Prev 21: 1002-1011.

Steenland K, Mannetje A, Boffetta P, Stayner L, Attfield M, Chen J, Dosemeci M, DeKlerk N, Hnizdo E, Koskela R, Checkoway H (2001) Pooled exposure-response analyses and risk assessment for lung cancer in 10 cohorts of silica-exposed workers: an IARC multicentre study. Cancer Causes Control 12: 773-784.

Stevens RG, Blask DE, Brainard GC, Hansen J, Lockley SW, Provencio I, Rea MS, Reinlib L (2007) Meeting report: the role of environmental lighting and circadian disruption in cancer and other diseases. Environ Health Perspect 115: 1357-1362.

Straif K, Baan R, Grosse Y, Secretan B, El Ghissassi F, Bouvard V, Altieri A, Benbrahim-Tallaa L, Cogliano V (2007) Carcinogenicity of shift-work, painting, and fire-fighting. Lancet Oncol 8: 1065-1066.

Walsh L, Dufey F, Tschense A, Schnelzer M, Sogl M, Kreuzer M (2012) Prostate cancer mortality risk in relation to working underground in the Wismut cohort study of German uranium miners, 1970-2003. BMJ Open 2: $\mathrm{e} 001002$. 